\title{
Does Ganja Cause Mental Illness? Perspectives from a Population-based Assessment of Mental Health Literacy in Jamaica
}

\author{
WD Abel, S Longman-Mills, J Martin, DC Oshi, P Whitehorne-Smith
}

\begin{abstract}
Objective: Mental illness is a major cause of morbidity and, globally, has a high lifetime risk. Mental health literacy is known to improve symptom recognition, care-seeking and treatment outcomes. This study therefore sought to assess the knowledge and beliefs of Jamaicans regarding the definition, aetiology, symptomatology, treatment and prevention of mental illness.

Method: A nationally representative, randomly selected sample of 1224 respondents completed a 50-item questionnaire in a cross-sectional survey in Jamaica.

Results: The highest proportion of respondents (31.9\%) defined mental health as a mad person/mentally disturbed' while 57.4\% defined mental illness as 'mad/mentally disturbed/not in the right mind'. Though the majority of the respondents believed that mental illness could be identified, perception of identification features varied: worrying (68.6\%), smoking ganja (62.3\%) and studying too much (47.9\%). Level of education and age were significantly associated with perceptions on ways to identify mental illness. Gender and educational level were significantly associated with perceptions on treatment and prevention of mental illness.

Conclusion: There was limited knowledge of the definition, aetiology, symptomatology, treatment and prevention of mental illness. Low mental health literacy was associated with having little or no formal education, being a male and being in the younger age group (15-29 years).
\end{abstract}

Keywords: Mental health, mental health disorder, mental health literacy, mental illness

\section{¿Genera la Marihuana Enfermedades Mentales? Perspectivas de una Evaluación Poblacional de los Conocimientos sobre Salud Mental en Jamaica}

\author{
WD Abel, S Longman-Mills, J Martin, DC Oshi, P Whitehorne-Smith
}

\begin{abstract}
RESUMEN
Objetivo: Las enfermedades mentales constituyen una de las principales causas de morbilidad $y$ - a nivel mundial - tienen un alto riesgo de por vida. Se sabe que el nivel de información y conocimientos sobre salud mental ayuda a reconocer los sintomas, buscar atención, y mejorar los resultados del tratamiento de las enfermedades mentales. Por lo tanto, el presente estudio estuvo encaminado a evaluar los conocimiento y creencias de los Jamaicanos en relación con la definición, etiología, sintomatología, tratamiento y prevención de las enfermedades mentales.

Método: Una muestra de 1224 encuestados a nivel nacional, seleccionada al azar, respondió un cuestionario de 50 peguntas de una encuesta transversal en Jamaica.
\end{abstract}

From: Department of Community Health and Psychiatry, The University of the West Indies, Mona, Jamaica, West Indies.
Correspondence: Professor W Abel, Department of Community Health and Psychiatry, The University of the West Indies, Mona, Kingston 7, Jamaica, West Indies. Email: drwendelabel@gmail.com 
Resultados: La mayor parte de los encuestados (31.9\%), definió la salud mental como 'loco/ con trastornos mentales', mientras que el 57.4\% definió la enfermedad mental como 'loco/ con trastornos mentales/no en su sano juicio'. Aunque la mayor parte de los encuestados creía que las enfermedades mentales podian ser identificadas, la percepción de las características de identificación percibidas variaba: preocupación (68.6\%), fuma de marihuana (62.3\%), y demasiado estudio (47.9\%). El nivel de educación y la edad estuvieron significativamente asociados con las percepciones de las formas de identificar las enfermedades mentales. El género y el nivel educacional estuvieron significativamente asociados con las percepciones sobre el tratamiento y la prevención de las enfermedades mentales.

Conclusión: Hubo un conocimiento limitado sobre la definición, etiología, sintomatología, tratamiento y prevención de las enfermedades mentales. El bajo nivel de información y conocimientos sobre salud mental estuvo asociado con el tener poca o ninguna educación formal, ser varón, y estar en el grupo de edad más joven (15-29 años).

Palabras clave: Salud mental, trastornos mentales, conocimientos sobre salud mental, enfermedades mentales

\section{West Indian Med J 2017; 66 (5): 554}

\section{INTRODUCTION}

Mental illness is globally recognized as a significant cause of morbidity with a lifetime risk of developing a mental disorder being as high as $50 \%(1,2)$. Consequently, the public health impact of mental illness cannot be overstated, as every other person is expected to have a direct and personal experience with a mental disorder. Treatment outcomes are improved when there is an understanding of the specific disorder as well as the recognition that mental disorders span across ages, genders and socioeconomic statuses. Unfortunately, even in developed countries, mental health literacy still remains low, negatively affecting symptom recognition and help-seeking for mental illness (3).

'Mental health literacy' includes the ability to recognize specific disorders, having knowledge of the risk factors, causes and available treatments, knowing how to seek mental health information, as well as attitudes that promote recognition and appropriate help-seeking behaviours (4). The need for mental health literacy has become a critical discussion within the public health arena, particularly as research has suggested that people's beliefs about the causes of mental illness affect their help-seeking behaviours, ie whether or not help is sought, the type of help that is sought and also their overall response to treatment $(3,5-7)$.

Available evidence indicates that sociodemographic factors, such as gender and age, play a significant role in mental health literacy. A 2012 study of mental health literacy and depression among the British population found that generally, respondents were more likely to identify females in vignettes as suffering from a mental illness than males, with men being more likely to indicate that the male did not have a mental health disorder (8). Among Chinese-speaking Australians, more female than male respondents could correctly identify mental health conditions; however, females also perceived medications to be relatively more harmful than their male counterparts (10). Additionally, significantly more males than females were found to adhere to traditional views on the causation of mental illness (9). Other studies which examined differences in mental health literacy among age groups have suggested that younger persons were more likely to identify mental health disorders correctly than older persons and were more likely to recommend persons to seek professional help $(10,11)$. However, there is a paucity of data regarding mental health literacy within the Caribbean.

Within the Caribbean island of Jamaica, strong traditional views are held on mental illnesses, with many ascribing the causes of mental illnesses to devil possession or obeah (sorcery). Consequently, the mentally ill are stigmatized, seen as being different and also devalued $(12,13)$. They are usually ostracized and sometimes blamed for their illness. However, over the years, with the implementation of numerous mental health campaigns, it is anticipated that mental health literacy within the Jamaican populace will be improved. Therefore, the purpose of this study was to determine the level of mental health literacy within the Jamaican population and to assess its associations with the sociodemographic factors of gender, age and level of education. The aspects of mental health literacy that are of interest to this study are the understanding of mental health and mental illness, as 
well as knowledge and perception of the causes, identification, prevention and treatment of mental illnesses.

\section{SUBJECTS AND METHODS}

This study was a nationwide, quantitative, cross-sectional household study conducted in 145 enumeration districts across Jamaica. The population targeted were household members between the ages of 15 and 65 years. The Statistical Institute of Jamaica randomly selected the enumeration districts and defined a starting point within each enumeration district.

A 50-item, semi-structured questionnaire was used as the survey instrument in this study. It captured information related to demographics, drug use patterns, knowledge of mental health, attitudes towards mental illness, and practices concerning mental health/illness. Data were collected in 1224 households. Definitions of 'mental health' and 'mental illness' were given by the respondents in their own words. During analysis, the definitions were quantified and categorized according to themes. In the descriptive data analysis stage, categorical variables were analysed by computing the frequencies and percentages while continuous variables were analysed by computing the means and standard deviations. Bivariate analysis was done using Pearson's Chi-square test. All data were analysed using the SPSS version 16 (IBM Inc, Armonk, New York, United States of America).

\section{RESULTS}

The sample consisted of 1224 participants, $72.6 \%$ of whom were female. The age range of the participants spanned from 15 years to over 60 years, with a mean age of 41.99 years (standard deviation: 15.9 years). The majority of the respondents had completed secondary school education (63\%), 27\% had completed primary school education, $7 \%$ had tertiary education while $3 \%$ had very little or no formal schooling.

Table 1 lists the definitions of 'mental health' and 'mentally ill' given by the respondents. Approximately $32 \%$ of the respondents reported that 'mental health' meant 'a mad person/mentally disturbed' while $12 \%$ stated that it meant 'someone with a mental disorder'. 'Mental illness' was defined in a similar way where the majority of the respondents $(57.4 \%)$ stated that it meant ' $\mathrm{mad} / \mathrm{mentally}$ disturbed/not in the right mind'. Age was significantly associated with perception of the causes of mental illness, with older respondents more likely to believe that studying too much would lead to mental illness $(p=0.005)$.

\section{Perceived causes of mental illness}

More than half of the respondents believed that "worrying' (68.6\%) and 'smoking ganja' (62.3\%) were the major causes of mental illness (Fig. 1). Chi-square analysis revealed that significantly more females $(76.8 \%)$ than males $(23.2 \%)$ believed that smoking ganja was a cause of mental illness $\left(\chi^{2}=19.035, p=0.000\right)$.

There were significant differences between level of education and perception of chemical imbalance and 'baby cold' (tradition has it that new mothers are encouraged to stay indoors for a few days so as not to catch a 'baby cold') as causes of mental illness (Table 2). There was also a significant difference between age groups and the perception of 'too much studying' as a cause of mental illness (Table 2).

\section{Perceived identification features of mental illness}

Most respondents (87.8\%) believed that mental illness could be identified, with significantly more females than males indicating that mental illness could be identified by the way it manifests in persons who have it $\left(\chi^{2}=10.684, p=0.005\right)$. Excessive violent/aggressive behaviour and display of confused thinking were the most commonly reported features of mental illness (Fig. 2). Similar to the association between gender and the possibility of identification of mental illness, gender was also significantly associated with perception of

Table 1: Respondents' definitions of mental health and mental illness by percentage

\begin{tabular}{lr}
\hline Respondents' definitions & \% \\
\hline Mental health & 31.9 \\
A mad person/mentally disturbed & 12 \\
Someone with a mental disorder & 9.9 \\
Sick in some way & 7.1 \\
Someone with a brain disorder & 6.5 \\
Keeping healthy and fit & 4.4 \\
State of mind of a person & 2.7 \\
Mental fitness & 19.9 \\
Other & 5.6 \\
Don't know & \\
& \\
Mental illness & 57.4 \\
Mad/mentally disturbed/not in the right mind & 12.7 \\
Sick & 9.2 \\
Someone with problems & 9 \\
Brain dysfunction & 5.1 \\
Strange/abnormal behaviour & 3 \\
Needing help/treatment from doctor & 2.7 \\
\hline Other & 0.7 \\
\hline
\end{tabular}




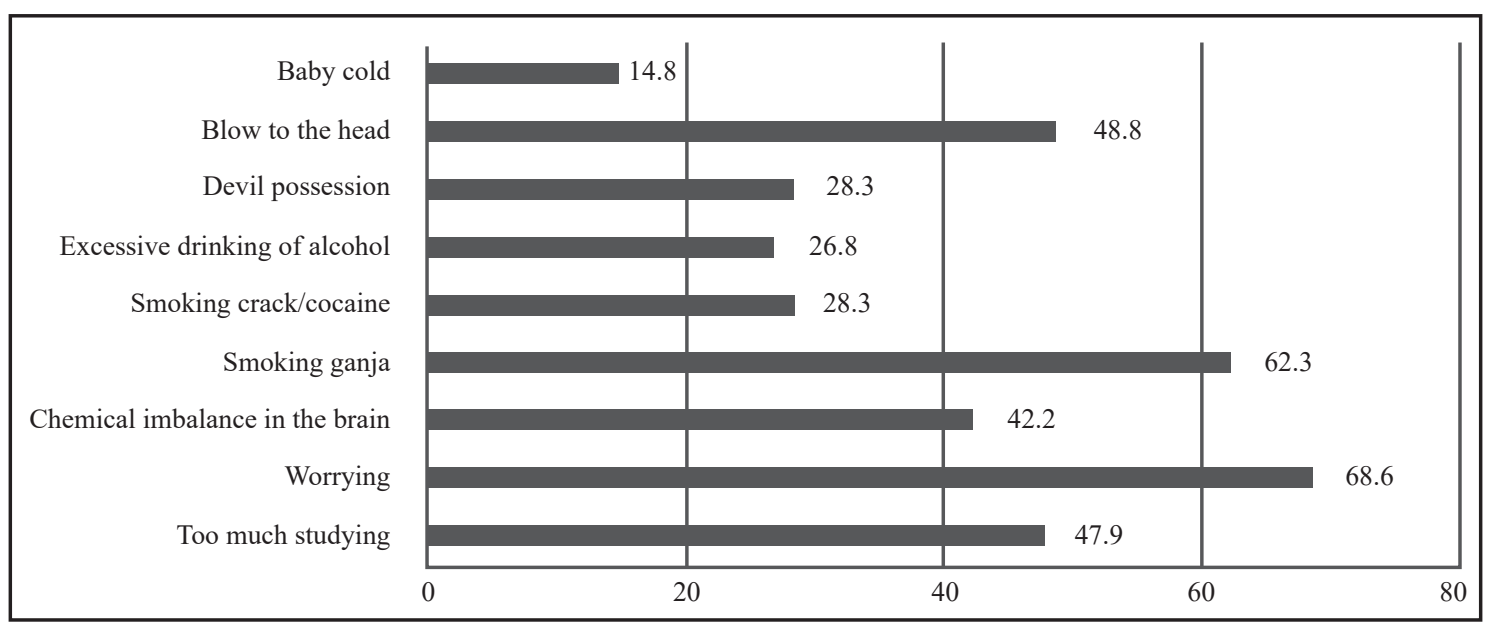

Fig. 1: Perceived causes of mental illness.

the ways to identify mental illness. Significantly more females $(74.9 \%)$ than males $(25.1 \%)$ believed that abuse of alcohol was a feature of mental illness $\left(\chi^{2}=8.205\right.$, $p=0.042)$. There was also a significant association between the level of education of the respondents and their beliefs about the identification of mental illness. Significantly lower proportions of respondents with little or no formal education believed that mental illness could be identified, and were less likely to cite features such as excessive violent/aggressive behaviour, display of confused thinking, long-lasting sadness/irritability, social withdrawal, and abuse of drugs and alcohol as ways of identifying mental illness (Table 3). Specifically, regarding abuse of drugs and alcohol, significantly higher proportions of females than males felt that it was a feature of mental illness $\left(\chi^{2}=8.205, p=0.042\right)$.

To examine more closely the influence of age on the perception of identification features of mental illness, our analysis focussed on the association between age and the perception of 'abuse of drugs and alcohol' and 'excessive complaints about physical problems' as identification features of mental illness (Table 4). It was observed that significantly lower proportions of the younger respondents (aged 15-24 years) held the view that mental illness could manifest as abuse of drugs and alcohol $(p=0.043)$. The same trend was also observed for the association between age and the perception of 'excessive complaints about physical problems' as an identification feature of mental illness $(p=0.03)$.

\section{Perceptions on treatment of mental illness}

Gender was significantly associated with perceptions on whether mental illness could be treated, with $78 \%$ of the females stating that mental illnesses were treatable $\left(\chi^{2}=6.490, p=0.039\right)$. There were no significant
Table 2: Significant differences between level of education and perceived causes of mental illness and between age and perceived causes of mental illness

\begin{tabular}{lll}
\hline \multirow{2}{*}{ Level of education } & \multicolumn{2}{c}{ Perceived causes } \\
\cline { 2 - 3 } None & Chemical imbalance & Baby cold \\
Primary & 55.6 & 29.4 \\
Secondary & 73.8 & 40 \\
Tertiary & 75 & 30.3 \\
Level of significance & 92.2 & 10.3 \\
& $0.004^{*}$ & $0.03^{*}$ \\
Age group (years) & & \\
\hline 15-19 & Too much studying \\
20-24 & 57.1 & \\
$25-29$ & 82 & \\
$30-34$ & 71.9 & \\
$35-39$ & 80.6 & \\
$40-44$ & 86.5 & \\
$45-49$ & 80.8 & \\
$50-54$ & 77.5 & \\
$55-60$ & 67.5 & \\
60 and over & 88.6 & \\
Level of significance & 80.7 & \\
\hline
\end{tabular}

* Level of statistical significance: $p<0.05$.

age differences in the perception of treatment of mental illness. However, there were significant differences seen across levels of education. Lower proportions of respondents with no formal education reported that prescribed drugs and psychotherapy could be used to treat mental illness. Generally, as the level of education of the respondents increased, the proportion who identified prescribed drugs and psychotherapy as ways to treat mental illness increased (Table 5). 


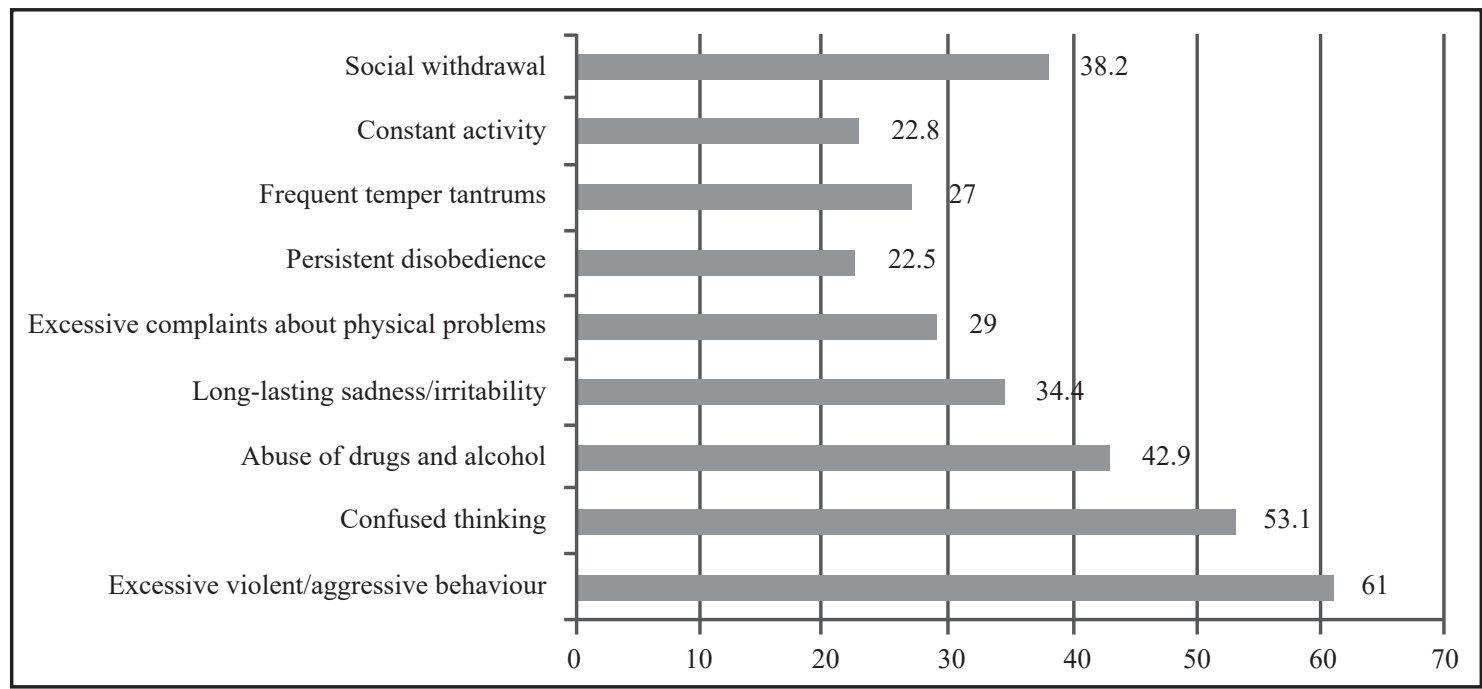

Fig. 2: Perceived ways to identify mental illness.

Table 3: Perceived identification features of mental illness by level of education

\begin{tabular}{|c|c|c|c|c|c|}
\hline \multirow[b]{2}{*}{ Identification of mental illness } & \multicolumn{4}{|c|}{ Level of education } & \multirow{2}{*}{$\begin{array}{l}\text { Level of } \\
\text { significance }\end{array}$} \\
\hline & None & Primary & Secondary & Tertiary & \\
\hline Can mental illness be identified? & 65.5 & 87.7 & 92.3 & 92.9 & 0.000 \\
\hline Excessive violent/aggressive behaviour & 60.9 & 84.8 & 80.8 & 80.9 & 0.028 \\
\hline Confused thinking & 50 & 75.1 & 75.9 & 79.7 & 0.008 \\
\hline Abuse of drugs and alcohol & 43.5 & 71.9 & 67.4 & 69.1 & 0.021 \\
\hline Long-lasting sadness/irritability & 31.8 & 63.7 & 54.9 & 63.3 & 0.002 \\
\hline $\begin{array}{l}\text { Excessive complaints about physical } \\
\text { problems }\end{array}$ & 30 & 58.1 & 47.5 & 44.7 & 0.012 \\
\hline Persistent disobedience & 25 & 47.1 & 34.3 & 39.6 & 0.002 \\
\hline Frequent temper tantrums & 10 & 47.5 & 44.4 & 57.1 & 0.001 \\
\hline Constant activity & 19 & 42.4 & 34.2 & 50.9 & 0.000 \\
\hline Social withdrawal & 30 & 61.7 & 57.1 & 79.3 & 0.000 \\
\hline
\end{tabular}

Table 4: Perceived identification features of mental illness by age group

\begin{tabular}{lcc}
\hline $\begin{array}{l}\text { Age group } \\
\text { (years) }\end{array}$ & $\begin{array}{l}\text { Abuse of drugs and } \\
\text { alcohol }\end{array}$ & $\begin{array}{l}\text { Excessive complaints } \\
\text { about physical } \\
\text { problems }\end{array}$ \\
\hline $15-19$ & 42.9 & 36.8 \\
$20-24$ & 53.7 & 35.9 \\
$25-29$ & 65.5 & 43.8 \\
$30-34$ & 72.1 & 50 \\
$35-39$ & 65.5 & 55.1 \\
$40-44$ & 73.8 & 55.4 \\
$45-49$ & 75.9 & 56 \\
$50-54$ & 62.4 & 41 \\
$55-60$ & 78 & 69.4 \\
60 and over & 71.8 & 52 \\
Level of significance & 0.043 & 0.03 \\
\hline
\end{tabular}

Table 5: Perceived ways to treat mental illness by level of education

\begin{tabular}{llllll}
\hline \multirow{2}{*}{$\begin{array}{l}\text { Perceived ways } \\
\text { to treat mental } \\
\text { illness }\end{array}$} & \multicolumn{5}{c}{ Level of education } \\
\cline { 2 - 5 } & None & Primary & Secondary & Tertiary & $\begin{array}{l}\text { Level of } \\
\text { significance }\end{array}$ \\
\hline Drugs & 70.4 & 81.5 & 82.2 & 93.6 & 0.03 \\
Psychotherapy & 31.8 & 64 & 67.7 & 80.3 & 0.001 \\
Nutrition & 40.9 & 55.6 & 48.5 & 54 & 0.038 \\
$\begin{array}{l}\text { Exercise } \\
\text { Spiritual }\end{array}$ & 40.9 & 50 & 42 & 46.8 & 0.033 \\
counselling & 39.1 & 66.4 & 63.4 & 60.7 & 0.041 \\
\hline
\end{tabular}

Significance level: $p<0.05$ 


\section{Perceptions on prevention of mental illness}

In terms of prevention of mental illness, $39.1 \%$ versus $36.5 \%$ of the respondents reported that mental illness could be prevented through 'positive thinking' and by eliminating worry, respectively (Fig. 3).

There were no significant gender or age differences regarding perceptions on prevention. However, there were significant differences seen across levels of education (Table 6). Significantly lower proportions of respondents with no formal education perceived 'positive thinking', 'eliminate worry' and 'eating right' as ways to prevent mental illness, compared to respondents with higher levels of education (Table 6).

\section{DISCUSSION}

The primary purpose of this study was to assess the knowledge and beliefs of Jamaicans regarding the definition, aetiology, symptomatology, treatment and prevention of mental illness. Although large proportions of the respondents were not able to define 'mental health' or 'mental illness' accurately and were unclear of the difference between these two concepts, most of them attributed mental illness to smoking ganja and worrying. Additionally, this study highlighted that the sociodemographic characteristics of gender, age and level of education did mediate the respondents' perception of the causes, identification, prevention and treatment of mental illness. More detailed discussions according to the main themes of the study follow.

\section{Perceived causes of mental illness}

Approximately $63 \%$ of the respondents attributed the aetiology of mental illness to 'smoking ganja' while $68.8 \%$ attributed it to 'worrying'. Almost half of the respondents indicated that 'too much studying' was a significant contributor to the development of mental illness. There was a significant gender difference highlighted, with more females than males stating that marijuana use/abuse was a major contributor to the development of mental illness $\left(\chi^{2}=19.035, p=0.000\right)$. This finding is consistent with observed gender differences in mental health literacy elsewhere $(14,15)$. However, contrary to the finding in this present study, some studies have reported no significant association between gender and mental health literacy $(16,17)$.

Age was significantly associated with perceptions on causes of mental illness. Previous studies have documented that lower age group is associated with better mental health $(6,18)$. Contrary to their findings, this present study found that younger respondents (aged 15-29 years) seemed to have less knowledge of the aetiology of mental illness, which is consistent with

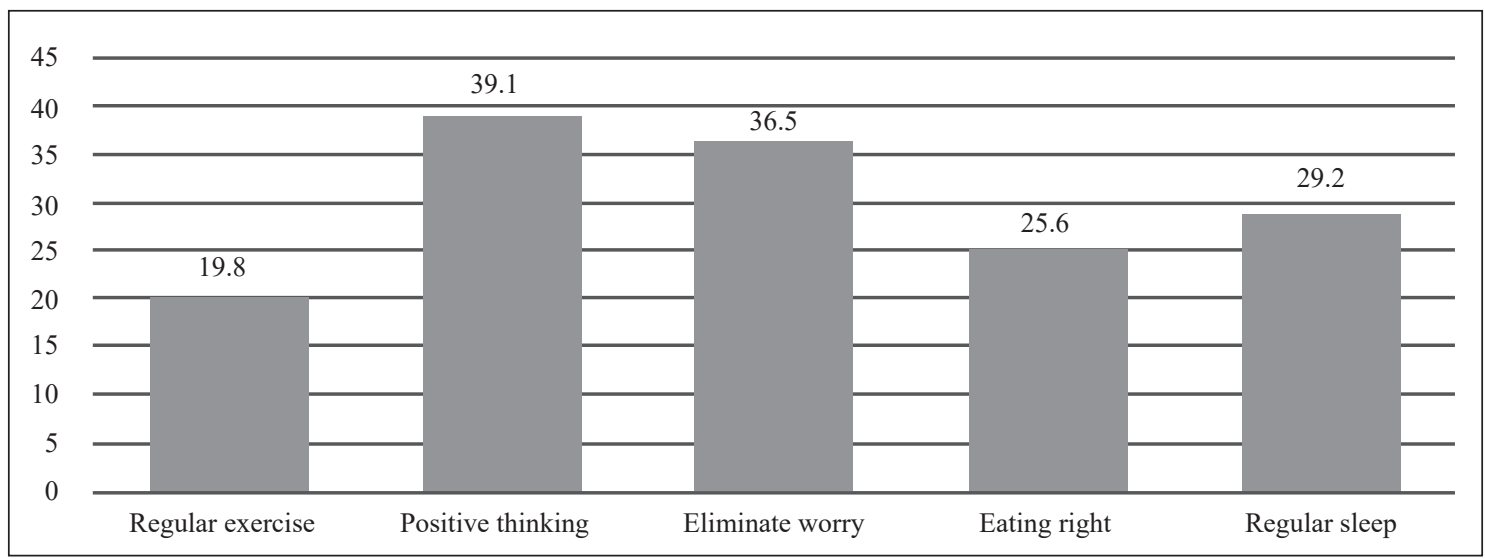

Fig. 3: Perceived ways to prevent mental illness.

Table 6: Perceived ways to treat mental illness by level of education

\begin{tabular}{llllll}
\hline & \multicolumn{4}{c}{ Level of education } & \multirow{2}{*}{ Perceived ways to treat mental illness } \\
\cline { 2 - 5 } & None & Primary & Secondary & Tertiary & Level of significance \\
\hline Positive thinking & 38.1 & 71.3 & 71.3 & 71.7 & 0.006 \\
Eliminate worry & 35 & 69.7 & 67.6 & 74.4 & 0.027 \\
Eating right & 55 & 63.4 & 47.1 & 63.2 & 0.015 \\
\hline
\end{tabular}

Significance level: $p<0.05$ 
a study of adolescents which found rather low mental health literacy among them (19). This age group would be expected to have more awareness of general health issues as well as mental health issues as apparently, they should have more access to information from various sources, such as electronic media, the internet and printed materials. Therefore, it is not clear why they should have lower mental health literacy compared to the older respondents. However, reasons may include inadequate information on mental health on mass media, inadequate mental health literacy programmes targeting this age group in their communities, probable general apathy to mental health issues among them, which implies that they may be attracted to information on other topical social issues rather than on mental health. An exploratory qualitative study may be needed to understand this phenomenon further.

Furthermore, the literature suggests that there is a wide chasm in mental health literacy among the levels of education as it relates to causes and treatment of mental illness (14). In this present study, persons with tertiary education $(92.2 \%)$ were more likely to accept chemical imbalance as against cultural nuances such as 'baby cold' held by those respondents with only primary education as the cause of mental illness. The recognition of a physiological basis for mental illness is likely to be due to a greater level of exposure to or awareness of mental health information.

\section{Perceived identification features of mental illness}

The results indicated that although most respondents reported that mental illness could be identified, a high proportion of respondents across all levels of education reported that excessive violent/aggressive behaviour and confused thinking were the primary symptoms exhibited by persons suffering from mental illness. This finding again points to the lack of understanding of mental illness among the general populace, especially as it relates to the symptomatology associated with mental illness. This finding corroborates the postulation that there is a clear discrepancy worldwide between psychiatric terms and the public's understanding of the terms (3). A significantly lower proportion of males believed that mental illness could be identified and were able to identify ways of identifying mental illness. This finding corroborates results from other studies which indicated that males were less likely to identify relevant symptoms associated with mental illness (9-11). Interestingly, though, a study in Western Jamaica on health literacy among persons with diabetes, and not on mental health, found no significant differences between males and females (14). The disparity in the findings might be because the respondents in this present study were from the general population while the respondents in the Western Jamaica study were selected from patients with diabetes receiving treatment at healthcare facilities. Logically, patients attending clinics may know more about their conditions.

Respondents' age played a role in the perception of ways to identify mental illness, with the younger age group displaying a lower awareness of symptoms of mental illness. As noted earlier regarding age and perceptions on aetiology of mental illness, the reasons for the lower mental health literacy among the younger age group are not known, but may be connected with their not being sensitized to seeking information on mental health online as well as inadequate presentation of mental health in electronic and print media and within their communities. This finding is at disparity with other studies which observed that younger age group was associated with better mental health literacy $(6,16-18)$. This present study found that the level of education of respondents influenced their perceptions on how mental illness could be identified. Consistent with other studies, respondents with a higher level of education had better knowledge on identification of mental illness (6, 16, 18). Conversely, significantly lower proportions of respondents with no formal education reported that mental illness could be identified. By corollary, lower proportions of respondents with no formal education indicated long-lasting sadness/irritability as a feature of mental illness, suggesting low mental health literacy in this sociodemographic group. This is probably due to their inability to read materials on mental health and the general tendency of this group to have less contact with the (mental) health services (15).

\section{Perceived treatment of mental illness}

Significantly higher proportions of respondents with tertiary education reported that mental illness could be treated with prescription drugs and psychotherapy. On the contrary, respondents with no formal education were less likely to identify prescription drugs and psychotherapy as treatment for mental illness. This finding is consistent with other studies in Jamaica which reported a positive correlation between a high level of education and high health literacy (16). Clearly, individuals with a higher level of education will have greater contact with (mental) health services and greater access to information on air (electronic mass media), online and in the print media. They are also more likely to get in contact 
with or be involved in any (mental) health programmes in their communities. Thus, while highly educated persons can obtain mental health information passively or actively via the aforementioned sources, those with little or no formal education may need to be explicitly targeted with culturally sensitive and context-specific mental health literacy programmes.

In relation to other sociodemographic characteristics, this present study found that gender was significantly associated with perceptions on whether or not mental illness could be treated (treatability), and on the use of bushes and herbs, ie complementary and alternative medicines (CAM), in the treatment. Significantly more females than males believed that mental illnesses were treatable and that CAM could be used in the treatment. Other studies also found that gender significantly influenced perceptions on mental illness $(14,15)$. In the Jamaican context, as in other societies, women tend to have more contact with the health services, and this may contribute to improving their mental health literacy.

Additionally, a significantly higher proportion of women than men had higher education as evidenced by $69 \%$ of women enrolling in tertiary institutions in 2010, with a female:male ratio of 41:18 (20). Further, it is not surprising that the respondents reported use of CAM as treatment for mental illness. Previous studies show that the prevalence of the use of CAM was high in Jamaica and that CAM was often used concomitantly with prescription drugs $(21,22)$. However, the finding in this present study differs from that in other studies which showed that men were more likely to use herbal preparations than women $(9,21,22)$. The reason for this disparity is not clear, but may be related to the ailment under study. The current study was about mental illness while the other studies were about diseases of other body systems such as the gastrointestinal system and the respiratory system $(21,22)$. This present study found no significant associations between age groups and the perceived treatment for mental illness, which is contrary to other studies which found significant associations between the age of respondents and their perceptions on treatment of mental illness $(10,11)$.

\section{Perceived prevention of mental illness}

This present study found no significant associations between gender or age and perceptions on the way that mental health could be prevented. However, there were significant differences in the perceptions on the prevention of mental illness among respondents with different levels of education. A greater percentage of respondents with little or no formal education reported that positive thinking, eliminating worry and eating right were effective ways of preventing mental illness. It is probable that folklore and traditional beliefs informed these perceptions rather than information obtained through contact with mental health services, mental health programmes and mass media. This suggests that mental health information, education and communication (IEC) messages might not have hitherto reached this sociodemographic group effectively.

\section{CONCLUSION}

The findings of this study suggested that the Jamaican population had limited knowledge on mental health. Low awareness/limited knowledge affected the major domains of aetiology, definitions, symptomatology, treatment and prevention of mental illness. Individuals with little or no formal education, who were male and who were in the younger age groups were disproportionately represented in the low mental health literacy segments of the society. Therefore, it is clear that there is a need for mental health literacy interventions in the Jamaican population. Context-specific and culturally sensitive programmes should be targeted at community members who have little or no formal education, who are in the younger age groups and who are male. General but simple measures such as providing pamphlets about mental health issues at doctors' offices and health centres and mass media programmes should be implemented to complement the more specific measures. Improved mental health literacy will likely result in better attitudes towards mental illness and improved help-seeking behaviour (23).

\section{REFERENCES}

1. World Health Organization. Global burden of disease. Geneva: WHO Health statistics and health information systems. Accessed March 15, 2011. Available from: http://www.who.int/healthinfo/global_burden_ disease/GBD_report_2004update_full.pdf?ua $=1$.

2. Kessler RC, McGonagle KA, Zhao S, Nelson CB, Hughes M, Eshleman $\mathrm{S}$ et al. Lifetime and 12-month prevalence of DSM-III-R psychiatric disorders in the United States: results from the national comorbidity survey. Arch Gen Psychiat 1994; 51: 8-19.

3. Rusch N, Muller M, Ajdacic V, Rodgers S. Shame, perceived knowledge and satisfaction associated with mental health as predictors of attitude patterns towards help-seeking. Epidemiol and Psychiatric Serv 2013; 23: $177-87$.

4. Jorm AF, Korten AE, Jacomb PA, Christensen H, Rodgers B, Pollitt P. Mental health literacy: a survey of the public's ability to recognise mental disorders and their beliefs about the effectiveness of treatment. Med J Aust 1997; 166: 182-6.

5. Picco L, Abdin E, Chong SA, Pang S, Vaingankar JA, Sagayadevan $\mathrm{V}$ et al. Beliefs about help seeking for mental disorders: findings from a mental health literacy study in Singapore. Psychiat Serv 2016; 67: 1246-53. 
6. Lim L, Goh J, Chan Y, Poon S. Mental health literacy and the belief in the supernatural. Open J Psychiat 2015; 5: 334-41.

7. Teferra S, Shibre T. Perceived causes of severe mental disturbance and preferred interventions by the Borana semi-nomadic population in southern Ethiopia: a qualitative study. BMC Psychiat 2012; 12: 79.

8. Swami V. Mental health literacy of depression: gender differences and attitudinal antecedents in a representative British sample. PLoS One 2012; 7: e49779.

9. Hadjimina E, Furnham A. Influence of age and gender on mental health literacy of anxiety disorders. Psychiat Res 2017; 251: 8-13.

10. Wong DFK, Lam AYK, Poon A, Chow AYM. Gender differences in mental health literacy among Chinese-speaking Australians in Melbourne, Australia. Int J Soc Psychiat 2011; 58: 178-85.

11. Farrer L, Leach L, Griffiths KM, Christensen H, Jorm AF. Age differences in mental health literacy. BMC Public Health 2008; 8: 125.

12. Williams D. Where do Jamaican adolescents turn for psychological help? Child and Youth Care Forum 2012; 41: 461-77.

13. Arthur CM, Hickling FW, Robertson-Hickling H, Haynes-Robinson T, Abel W, Whitley R. 'Mad, sick, head nuh good': mental illness stigma in Jamaican communities. Transcultural Psychiat 2010; 47: 252-75.

14. Khan TM, Sulaiman SA, Hassali MA. Mental health literacy towards depression among non-medical students at a Malaysian university. Ment Health Fam Med 2010; 7: 27-35.

15. Yuan Q, Abdin E, Picco L, Vaingankar JA, Shahwan S, Jeyagurunathan A et al. Attitudes to mental illness and its demographic correlates among general population in Singapore. PLoS One 2016; 11: e0167297.
16. Singh SG, Aiken J. The effect of health literacy level on health outcomes in patients with diabetes at a Type $\mathrm{V}$ health centre in Western Jamaica. Int J Nurs Sci 2017; 4: 266-70.

17. Furnham A, Annis J, Cleridou K. Gender differences in the mental health literacy of young people. Int J Adolesc Med Health 2014; 26: 283-92.

18. Chong SA, Abdin E, Picco L, Pang S, Jeyagurunathan A, Vaingankar JA et al. Recognition of mental disorders among a multiracial population in Southeast Asia. BMC Psychiat 2016; 16: 121.

19. Lam LT. Mental health literacy and mental health status in adolescents: a population-based study. Child Adolesc Psych Mental Health 2014; 8: 26.

20. United Nations Statistics Division. Statistics and indicators on women and men: education. 2012. Accessed September 7, 2017. Available from: https://unstats.un.org/unsd/demographic/products/indwm/default.htm.

21. Delgoda R, Younger N, Barrett C, Davis D. The prevalence of herbs use in conjunction with conventional medicines in Jamaica. Complementary Therapies Med 2010; 18: 13-20.

22. Picking D, Younger N, Mitchell S, Delgoda R. The prevalence of herbal medicine home use and concomitant use with pharmaceutical medicines in Jamaica. J. Ethnopharmacol 2011; 137: 305-11.

23. Rüsch N, Evans-Lacko SE, Henderson C, Flach C, Thornicroft G. Knowledge and attitudes as predictors of intentions to seek help for and disclose a mental illness. Psychiat Serv 2011; 62: 675-8. 